committee functions of the College. New lighting and heating systems will also be installed throughout the building and the kitchen will be enlarged.

The President will be convening a small Working Party to prepare a College statement on the various problems with confidentiality which are causing much concern to the membership.

The Court of Electors met in February and approved the Report on SHO and Registrar Training in Social and Community Psychiatry prepared by that Section. This will shortly be published in the Bulletin. The Court is discussing the various possibilities for increasing the activities of the College overseas and will be preparing a report in due course. Council approved the Notes of Guidance for
Regional Advisers: Consultant Posts in Alcohol and Drug Dependence, and has agreed that this will be published in the Bulletin.

I would like to thank Dr Fowlie and all his staff for the excellent hospitality they have offered the members of the College during our stay in Aberdeen.

Elections will be held shortly for the Office of Dean, for members of Council and for the Court of Electors. The closing date for nominations is 15 April. Finally I am sure you would all like to join me in congratulating Dr James Birley on his election as President.

Prof. R. G. Priest Registrar

\title{
Private Care for the Elderly Mentally IIl
}

\section{Report of a Working Party of the Section for the Psychiatry of Old Age}

The principal recommendations in this report are as follows:

1. Those who seek to enter private care with the assistance of public funding should be offered careful medical, psychiatric, nursing and social screening, wherever possible before admission.

2. To assist in this process, an attempt should be made, in collaboration with representatives of the Royal College of General Practitioners, the British Geriatrics Society, and the Association of Directors of Social Services, to develop a screening procedure which would reliably indicate medical, psychiatric, and social needs.

3. Mentally ill old people resident in private homes should be offered surveillance, treatment and rehabilitation by local psychogeriatric services who should also offer counselling to managers and care staff in homes which accommodate such patients.

4. The level of financial support for residents should be determined more flexibly, so that the amount paid reflects both the nature of a resident's needs for care, and the local cost of providing this to an acceptable standard.

5. Methods should be found to bring the statutory and non-statutory sectors closer for the purpose of planning care for the elderly infirm.

6. Where provision of private care greatly exceeds local need, the implication for the local health service should be very carefully considered in planning applications for the development of residential or nursing homes.

7. A third party inspectorate should be created to monitor standards of care nationwide.

8. Emphasis upon private care in homes for the elderly should not deflect attention and resources from the need to develop better treatments and rehabilitation for those with mental illness, nor the need to provide more effective systems of care to the patient's own homes.

9. Consideration should be given to extending the period of notice of closure from three to six months.

\section{Introduction}

Care for large numbers of old people in private homes, but at the public expense, is a recent phenomenon. In 1978, just 7,000 were so supported, receiving benefits averaging £15.71 per head, the total cost to the Exchequer being $\mathrm{f6m}$. Six years later, the number had increased sixfold to 42,500 , and the annual cost had risen to $1190 \mathrm{~m}$.

This development has proceeded at different rates across the nation, being fastest in the South-East and in traditional retirement areas. Where the expansion has been rapid, marked effects on the management and discharge of elderly mentally ill people from psychiatric departments have been reported by members of the College Section for the Psychiatry of Old Age.

In response to this new situation, a working party of the Section was established and set certain tasks, which were as follows:

(i) To examine the rate of expansion both locally and nationally;

(ii) to collect information on the effects of a growing private sector upon psychogeriatric practice and the care of the elderly mentally ill;

(iii) to study Government legislation concerning the registration of private residential and nursing homes;

(iv) to consider ways in which standards of care might be monitored;

(v) to review documents (a) supportive and (b) critical of the growth of private care at public expense;

(vi) to consider the longer term implications of a development which might lead to a situation where the private sector became the largest care giver, at least within institutions, to the elderly mentally ill.

Method

The working party met four times, and took oral and written evidence. 
The report itself is presented under the following headings:

(i) The present situation vis à vis private care (as at Autumn 1985).

(ii) perceived advantages of the expansion of care in the private sector;

(iii) perceived disadvantages of the above;

(iv) recommendations in detail;

(v) a summary of the recommendations in abbreviated form.

\section{The present situation}

1. At the end of 1984 , there were 42,500 old people in private homes, supported by DHSS funds at the rate of $£ 88.00$ per capita, the total annual cost being $1190 \mathrm{~m}$. This was expected to rise by a factor of $50 \%$ in $1985 .{ }^{1}$

2. Homes are now registered either with the local authorities in the case of residential homes, or the district health authorities in the case of nursing homes. ${ }^{2}$

3. Registering authorities have a duty to inspect registered premises annually, and while standards are set locally, guidance is available to assist in this; Home Life being the guide for local authorities, the HAHA Handbook for health authorities.

4. There is no provision for pre-admission screening of residents, and some evidence that residents in nursing homes do not require that intensity of support. ${ }^{3}$

5. Most of the homes provided are small, and the buildings used are conversions rather than new developments. Consequently, development in a given locality can depend more upon the availability of suitable premises for conversion, rather than local need. Large and relatively inexpensive country houses are sometimes favoured, though these may be a long way from where the residents once lived.

6. In April 1985, national limits for board and lodging allowances were set by the Secretary of State. ${ }^{4}$ These are (25 November, 1985) $£ 120$ per week to $£ 180$ per week in residential homes and $£ 170$ per week to $£ 230$ per week in nursing homes. Figures for the mentally ill are $£ 130$ in residential and $£ 180$ in nursing homes.

7. So far as the elderly mentally ill are concerned, all but the most severely demented enter residential homes, usually not specifically designated for the care of mentally ill people. Proprietors in some areas consider that $£ 120$ per week does not adequately recompense them for caring for a demented person, and one effect of the National Limit has been to discourage the entry of demented people to private care.

8. There is concern, largely anecdotal but probably true, that some proprietors lack skill in managing the elderly mentally ill, and use psychotropic drugs unskillfully. Most reports concern the withholding of antidepressants given at bed-time in those patients who sleep soundly! Patients known to psychiatric services are often located in homes a long way away, so that follow-up of cases is difficult.

9. A joint central and local government working party has suggested that residents should be screened before admission, but proposed that screening methods be piloted in selected areas before being implemented nationally.

Perceived advantages of private institutional care

1. Potential patients and residents and their relatives are offered a wider range of choices of types of home and location of homes.

2. The new development has expanded the quantity of institutional care in districts where this was probably inadequate, notably in traditional retirement areas.

3. Some teams working with the elderly mentally ill have noted a redistribution of their work away from continuing care and towards more active treatment and rehabilitation. Turnover in some units has been enhanced.

4. Some private homes offer more privacy than is possible on many chronic wards within the health service.

5. The private sector has expanded to meet the demand for additional places more rapidly than the public sector could have done.

6. Because the capital resource for these homes has been obtained from the private sector, and Government, through supplementary benefit has funded the running costs (which of course take into account the cost of borrowing) at least in the early stages, the cost to the public purse, per bed provided, has been lower.

7. Some private residential home managers have adopted a flexible approach to problems such as incontinence, and have been willing to accept residents refused by local authority home managers.

8. Once accepted in principle for private care, proprietors often arrange transfer quickly, and without the sometimes excessive bureaucratic delays encountered before people can move to local authority homes.

9. The development of small homes, often popular with patients and their relatives, has demonstrated a gap in the statutory service provision in many districts.

\section{Perceived disadvantages}

1. Residents and patients are rarely screened before admission. This situation contrasts with the relatively rigorous medical examination which precedes the granting of an attendance allowance and the medical and social investigations carried out by many local authorities before clients are accepted for residential care.

There are four consequent disadvantages:

(a) treatable medical disorders remain undiscovered;

(b) an opportunity to consider alternative care systems is lost;

(c) mildly disabled people may be offered expensive supports which they do not require;

(d) very severely disabled people may be placed in homes unable to meet their medical and nursing needs.

2. Waste of public money because of overcharging (in some areas) and unnecessary provision of high 
dependency care (evidence on this is scanty, but Ann Capewell's study demonstrated that $30 \%$ of people in nursing homes in Edinburgh did not need that intensity of care). ${ }^{3}$

3. Homes are often located at a distance from the client's preferred residence (perhaps particularly in rural areas where distant large country houses, cheaply available, are often developed as private homes).

4. Relatives may find it (a) expensive or (b) practically difficult to keep in touch; another feature of the country house establishment referred to above.

5. Homes can accumulate in one locality, creating geriatric ghettos with consequent problems for medical care and Local Authority Social Services resources.

6. Placing patients at a distance can cause discontinuity of medical care; patients with serious mental illness problems of some complexity can be transferred to another general practitioner's list in another psychiatrist's sector, rarely to the patient's advantage.

7. The development has occurred completely without the NHS local authority and/or joint planning processes and makes a nonsense of such procedures. A common response at district level has been to delay or shelve proposed developments and adopt a 'wait and see' policy.

8. Prior to the recent legislation, yet to be fully implemented, residential homes have often not been properly inspected. Indeed, establishing adequate inspection procedures is likely to be very difficult and will generate a new bureaucracy (evidence from the USA reveals that this can be both complex and expensive both in terms of cost and use of skilled personnel).

9. Residents in private residential homes are seldom adequately documented nor are proper records kept of medication given. It has been suggested to us that managers may alter or withold medication in ignorance of its true purpose.

10. Multiple ownership: some members report initially keen and dedicated owner managers acquiring additional homes, putting in less skilled managers and becoming increasingly remote from control of everyday standards and complainants.

11. Many managers have little interest or skill in the management of those residents with mental disorders.

12. The rehabilitation professions (occupational therapists, specialist nurse therapists, e.g. incontinence nurses and physiotherapists) are conspicuous by their absence.

13. High quality care is less profitable; teenage care attendants (not necessarily poor caregivers) on Government schemes are the best bet in financial terms, but the policy encourages high staff turnover.

14. Some local authorities are using the new development as an excuse for opting-out of their own responsibilities and are closing Part III homes as quickly as possible. The Department of the Environment pressures on local authorities to restrict spending is encouraging this.

15. The patterns of care offered are generally less flexible.
Respite beds, so helpful to relatives caring for the disabled, are net loss makers so proprietors generally are not interested in providing them in a way that encourages pre-planned respite care.

16. Loss of trained staff from NHS and LASS services to the private sector (normally as proprietors) has led to a loss of key personnel from the public sector. This movement is difficult to measure but may be considerable.

17. Other Health and Social Security staff have joined the 'black economy' and are 'moonlighting' in private homes; some who have become proprietors continue to work in the statutory services where they are called upon to make judgements about patient care in which they may have a vested interest.

18. Residents in private homes have little security of tenure. A proprietor is required to give just three months notice of closure.

19. Liaison between the psychogeriatric team and the private sector is generally perceived to be more difficult than with the public and voluntary sectors.

20. Changes in ownership can lead to changes in style of management and in the selection of patients/residents regarded as appropriate.

21. Safeguards for resident's financial and legal rights are less rigorous in certain private homes.

\section{Proposals}

Assessment We strongly endorse the view, recently expressed by the Joint Central and Local Government Working Party under the title Supplementary Benefit and Residential Care, that people should be properly assessed before they are admitted to any form of institutional care. Multidisciplinary assessment should take into account both the social and medical status of the proposed resident/ patient and should include the active consideration of medical treatment or rehabilitation and of alternative systems of community-based care.

(i) The medical assessment should be by doctors appropriately trained and approved for this purpose. This might be the patient's GP but there are arguments in favour of an independent assessment. Practitioners holding the Diploma of Geriatric Medicine of the Royal College of Physicians might be appropriately selected for this purpose, as might other practitioners with experience and/or training in geriatric medicine or the psychiatry of old age.

(ii) Where the assessing doctor finds medical or psychiatric problems which require further assessment and/ or may prove amenable to treatment, his findings should be reported to the patient's own general practitioner. In these circumstances, and especially where a treatable disorder is suspected, the person should not be admitted to care on anything other than a shortterm basis, and his or her home should be retained until investigation and appropriate treatment are complete.

(iii) District-based geriatric and psychogeriatric teams should assist in the above process by: 
(a) offering appropriate training to doctors seeking approval as assesssors;

(b) offering advice, as appropriate, to medical assessors-especially on the medical status of the patients already known to the teams;

(c) offering assessments and treatments to patients identified as a result of this process.

Inspection We endorse the guidelines for inspection contained in Home Life and in the NAHA Handbook. ${ }^{3.6} \mathrm{We}$ consider that these should be applied also to the corresponding statutory facilities (long-stay wards for the elderly; nursing homes provided by the NHS; and residential homes provided by local authorities).

We consider that a third party inspectorate is needed for the non-statutory sector, analogous to the Health Advisory Service. This could be a new body, or these functions might be assumed also by the HAS along with Social Services Inspectorate of the DHSS. In any case these two latter bodies would be well placed to advise on the constitution, membership and modus operandi of such a body. Adequate funding derived from the institutions to be inspected would, of course, be needed.

Payments The present ceiling on supplementary benefit for those living in private residential homes is too low. Section members have indicated that they refer many moderately infirm patients (mainly cases of dementia) to such establishments because they do not warrant the full resources of a nursing home. Nevertheless, such people do require a good deal of careful supervision and may be less rewarding to care for than the physically frail but cognitively intact. Low levels of benefit may discourage proprietors from taking in for care less rewarding and more difficult people and many members have given evidence that 'dements' are already being rejected.

Indeed, we doubt the wisdom of setting a 'national figure'. We advocate rather a system of weightings which will reflect regional differences in the cost of buying and converting suitable premises and providing care for residents to the required standard; the staffing of homes varies considerably, being highest in the south where the proportions of frail elderly are highest. Now that responsibility for setting levels of benefits rests with the Secretary of State, we hope that he will introduce a system of 'weightings' which reflect at least regional differences in the cost of providing care to a required standard. The level of benefit should also acknowledge the level of care needed, e.g. higher benefit for those suffering from dementia.

Links with statutory services We propose that homes which provide accommodation for elderly mentally frail people should be supported by local psychogeriatric teams. Teams might provide support in several ways including:

(i) visiting frail residents and offering advice on care and management of mental disorders;

(ii) offering in-service training to staff; (iii) offering advice on individual and group activities likely to maintain mental health of residents;

(iv) offering support to care staff by individual or group supervision; advice and counselling;

(v) arranging treatment and rehabilitation for residents as appropriate.

This cannot be achieved without substantially strengthening existing local psychogeriatric teams. All team members are likely to be involved in support to some extent, but those most involved are likely to be community psychiatric nurses, occupational therapists, psychologists, social workers, physiotherapists and consultant psychogeriatricians. This proposal is obviously dependent on the establishment of a specialist team for the elderly mentally ill in each health district, and will demand that the key disciplines mentioned above will need to be represented in sufficient strength to fulfil the needs for training, re-assessment and support.

\section{Planning links}

(i) Methods should be found to bring the statutory and non-statutory sectors closer together for the purpose of planning care for the elderly infirm. In a situation where more than half the residential provision is likely to be based in private or voluntary homes by the year 1990 , to plan the public sector (DHA and LASSD) without an input from the non-statutory care providers is clearly unsatisfactory. Private nursing homes offering a high standard of care might, for example, be recognised for nurse training.

(ii) Where provision of private care greatly exceeds local need, the implication for local health services should be very carefully considered in planning applications for the development of residential or nursing homes.

\section{Other recommendations}

(i) Representatives of the Royal College of Psychiatrists, the Royal College of General Practitioners, the Association of Directors of Social Services and the British Geriatrics Society should give further consideration to the development of a nationally accepted screening instrument which would:

(a) help to identify potentially treatable disorders;

(b) estimate degree of handicap;

(c) indicate the most appropriate type of care required.

(ii) The development of private care at public expense should not deflect interest or resources from developing better strategies for the care of the elderly mentally ill in the public sector.

(iii) There is a need for an agreement on the course to be followed when an old person, identified as mentally ill and receiving treatment from a district psychogeriatric service, is placed in a private home in a nearby health district. This should cover not only the type of information to be passed on with the patient to the medical staff in the district but some willingness to 
accept responsibility for reassessment of patients found to be unsuitable for care in the home within an agreed period of placement, generally six months.

\section{Concluding remarks}

This document has been produced against the background of a rapidly changing situation. It is offered because the private sector increasingly provides care for arguably the most vulnerable section of the population, the elderly mentally ill. It is hoped that discussions will arise from this document which will further clarify the issues we have raised-for proper assessment before placement; for treatment and rehabilitation as well as care; for care in environments which meet the needs and wishes of elderly people, where they might find a secure haven, free from the risk of exploitation. We also hope to see a real dialogue developing between the private and public service care provides on issues such as the planning and operation of care services for the elderly with mental disorder.

Approved by Council March 1987
REFERENCES

'Chancellor's Statement: Social Security (1984) Press Release, Department of Health and Social Security, 12 November 1984.

${ }^{2}$ Registered Homes Act (1984) Chapter 23, including statutory Instruments No 1346 and No 1348(C29).

${ }^{3}$ Capewell, A. E., Primrose, W. R. \& Macintyre, C. (1986) Nursing dependency in registered nursing homes and long-term geriatric wards in Edinburgh. British Medical Journal, 292, 1719-1721.

4Supplementary Benefit and Residential Care (1985) Report of a Joint Central and Local Government Working Party.

${ }^{5}$ Home Life: A Code of Practice for Residential Care (1984) Report of a Working Party sponsored by the DHSS and convened by the CPA; published by the Centre for Policy on Ageing.

'National association of Health Authormties (1985) Registration and Inspection of Nursing Homes: A Handbook for Health Authorities.

\title{
Psychiatrists and General Management
}

\author{
David TAIT, Consultant Psychiatrist, Murray Royal Hospital, Perth PH2 7BH; Chairman, Management Group, \\ Scottish Division
}

Those who distrust the 'straw poll' at the party conference or outside the polling station should not read on, those who feel that such exercises can be illuminating may be interested in the following impression of Scottish psychiatrists' views on general management.

The Study

At the Quarterly Meeting of the Scottish Division of the Royal College of Psychiatrists on 5 December, 1986 the author gave out a questionnaire on behalf of the newlyformed Management Group. Thirty-seven questionnaires were returned, completed to various degrees; the respondents included 25 Consultants, one Medical Commissioner from the Mental Welfare Commission, three Senior Registrars and six Registrars. Although less than $10 \%$ of Scottish psychiatrists' views are presented, they came from 20 different services, about half the total in the country. The questionnaire was discussed and completed during one part of the meeting. Many respondents replied only in part, and most questions permitted more than one response to the 'stem', so it is the proportion of yes to no answers which is of most interest.
1. The Griffiths ideology

Do you think the Griffiths proposals are:

a) Irrelevant to the NHS?

(b) May enhance patient care through better management?

(c) May damage patient care through inappropriate management?
YES NO

32

$31 \quad 2$

27
These results seem clear cut-only two respondents thinking Griffiths' ideas are irrelevant, only two thinking they are powerless to improve patient care, only six believing they can do no harm. The commonest pattern of replies to the question (from 22 of 37 respondents) was no-yes-yes; Scottish psychiatrists clearly see Griffiths as relevant, and powerful for good or evil. This most recent reorganisation is certainly not viewed as merely cosmetic. 